\title{
ETHOS EM INTERAÇÃO: O DEBATE POLÍTICO-ELEITORAL ENTRE EDUARDO PAES E WILSON WITZEL EM 2018
}

\author{
Interactional Ethos: The Political \\ and Electoral Debate between \\ Eduardo Paes and Wilson Witzel in 2018 \\ Ethos en interacción: el debate \\ político-electoral entre \\ Eduardo Paes y Wilson Witzel en 2018
}

\section{Wagner Alexandre dos Santos Costa*}

Universidade Federal Rural do Rio de Janeiro, Instituto de Ciências Humanas e Sociais, Departamento de Letras e Comunicação, Seropédica, RJ, Brasil

\begin{abstract}
Resumo: No debate de segundo turno das eleições de 2018, enfrentaram-se os candidatos Eduardo Paes (DEM) e Wilson Witzel (PSC). Tendo em vista que no debate político-eleitoral o interesse é triunfar sobre o adversário, a imagem de si, prévia ao discurso ou propriamente nele desenvolvida, muitas vezes determina o sucesso da adesão de um auditório e o consequente sucesso de um projeto de dizer empreendido com certa finalidade. A proposta de estudo é analisar a tensão decorrente do jogo de imagens projetadas no debate político-eleitoral/2018, dando enfoque às situações de luta discursiva da etapa de segundo turno das eleições ao cargo de Governador do Estado do Rio de Janeiro. Para tanto, alia os quadros teóricometodológicos dos estudos do ethos em interação (KERBRAT-ORECCHIONI, 2016; CHANAY; KERBRAT-ORECCHIONI, 2007) e da análise semiolinguística do discurso político (CHARAUDEAU, 2016, 2011).
\end{abstract}

Palavras-chave: Ethos. Interação. Debate.

\begin{abstract}
In the second round debate of the 2018 elections, the candidates Eduardo Paes (DEM) and Wilson Witzel (PSC) faced each other. Bearing in mind that the interest in the political and electoral debate is to triumph over the adversary, the sel-image - prior to the speech or properly developed in it -, often determines the successful adherence of an of an audience and the eventual success of a project of saying undertaken with a certain purpose. Our study proposes an analysis over the tension resulting from the image maneuvering projected in the debate of 2018, focusing on the situations with discursive tension in the second round of the election process to the position of Governor of the State of Rio de Janeiro. In order to do that, we aligned the theoretical and methodological bases from the studies of the interactional ethos (KERBRAT-ORECCHIONI, 2016; CHANAY; KERBRAT-ORECCHIONI, 2007) with the semiolinguistic analysis of the political discourse (CHARAUDEAU, 2016, 2011).
\end{abstract}

Keywords: Ethos. Interaction. Debate.

Resumen: El debate de la segunda ronda de las elecciones de 2018, se enfrentaron los candidatos Eduardo Paes (DEM) y Wilson Witzel (PSC). Observándose que en el debate político-electoral lo interés es triunfar sobre el adversario, la imagen de si, previa del discurso o propiamente en él desarrollada, muchas veces determina el suceso de la adhesión de un auditorio y el consecuente suceso de un proyecto de decir emprendido con alguna finalidad. La propuesta de estudio es analizar la tensión consecuente del juego de imágenes proyectadas en el debate político-electoral/2018, enfocándose las situaciones de lucha discursiva

* Doutor em Estudos da Linguagem e docente do Mestrado Profissional em Letras da Universidade Federal Rural do Rio de Janeiro (UFRRJ). ORCID: https:orcid.org/0000-0003-4804-6561. E-mail: wagnercosta.prof@gmail.com. 
de la etapa de segunda ronda de las elecciones para el cargo de Gobernador del Estado de Rio de Janeiro. Para ello, alía los cuadros teórico-metodológicos de estudios del ethos en interacción (KERBRATORECCHIONI, 2016; CHANAY; KERBRAT-ORECCHIONI, 2007) y del análisis semiolingüística del discurso político (CHARAUDEAU, 2016, 2011).

Palabras clave: Ethos. Interacción. Debate.

\section{INTRODUÇÃO}

No ano de 2018, no processo eleitoral ao cargo de Governador do Estado do Rio de Janeiro, no segundo turno, confrontaram-se os candidatos Wilson Witzel, do Partido Social Cristão (PSC), e Eduardo Paes, do Democratas (DEM). O debate final entre os concorrentes aconteceu em 25/10/2018, nos estúdios da Rede Globo de Televisão e foi transmitido ao vivo para todo o Estado do Rio de Janeiro.

A ocasião foi marcada pela tensão causada por um resultado da prévia eleitoral que levou à decisão dois candidatos, dos quais um, Wilson Witzel, que não possuía expressão nas pesquisas de intenção de voto, foi o grande vencedor do primeiro turno, obtendo $41,28 \%$ dos votos válidos, contra os 19,56\% de Eduardo Paes, segundo colocado. Houve, então, uma configuração diferente da polarização, grosso modo, esquerda $x$ direita aguardada na disputa, pois as duas legendas, com alguma variação, caracterizam-se como de centro-direita. Em decorrência disto, o debate não se assinalou propriamente como um confronto entre as diretrizes ideológicas das legendas, mas teve seu curso centrado individualmente em cada candidato.

Assim, além de defender seus programas de governo, os candidatos precisavam gerenciar a imagem de si que construíam para o grande público, bem como descredibilizar a imagem do adversário. Estudiosos de práticas interacionais em debates políticos, como Kerbrat-Orecchioni (2016), afirmam que esse é um gênero tipicamente orientado para o desacordo.

Fazia-se necessária a construção de ethé que sustentassem a credibilidade desenhada pelos candidatos. No entanto, como a formulação dessa imagem se dava em pleno curso de uma atividade interacional, face a face com o adversário, não se tratava de algo que pudesse simplesmente transcorrer de acordo com um plano prévio. Estava articulado o confronto discursivo.

Nossa proposta de estudo, dessa forma, consiste em analisar a tensão decorrente do jogo de imagens projetadas no debate político-eleitoral/2018 pelos candidatos Wilson Witzel e Eduardo Paes, dando enfoque às situações de embate discursivo da etapa de segundo turno das eleições ao cargo de Governador do Estado do Rio de Janeiro. Especificamente, busca-se compreender a) como cada candidato mobiliza detalhes da identidade do adversário para apoiar ou refutar determinados tipos de ethé; b) a importância do ethos pré-construído no debate; c) o papel da imagem atribuída como estratégia de descredibilização do adversário.

Para sustentar a proposta de estudo, aliamos os quadros teórico-metodológicos dos estudos do ethos em interação (KERBRAT-ORECCHIONI, 2016; CHANAY e KERBRAT-ORECCHIONI, 2007) e da análise semiolinguística do discurso político (CHARAUDEAU, 2016 e 2011, entre outros). 
Observamos e coletamos dados da formação desse ethos, que é, no caso estudado, resultante (ou se forma, se constrói a partir) de vários aspectos, tais como o conteúdo das falas dos candidatos e detalhes de suas características físicas (compleição corporal) por meio de suas expressões faciais e corporais. O estudo assume caráter qualitativo, sendo os dados interpretados na articulação entre a teoria e as informações contextuais do debate, cujo vídeo ${ }^{1}$ encontra-se disponível na plataforma YouTube.

Inicialmente, neste artigo, explicitaremos o conceito de ethos, dando relevo à sua concepção no quadro de estudos da Análise Semiolinguística de Discurso. Dado o caráter interacional da situação comunicativa do debate político-eleitoral, elegemos o quadro teórico complementar do estudo do ethos em interação. Em seguida, analisamos o debate a partir de trechos transcritos livremente, pois para o estudo não foram considerados dados obtidos da fala stricto sensu. Por fim, seguem-se as considerações finais e as referências utilizadas no estudo.

\section{O CONCEITO DE ETHOS}

Segundo Amossy (2004), o termo ethos foi emprestado da retórica antiga e retomado em ciências da linguagem. Tal noção "designa a imagem de si que o locutor constrói em seu discurso para exercer uma influência sobre seu alocutário.” (p. 220).

$\mathrm{Na}$ década de 1950, o estudo da retórica ressurge renovado a partir da publicação da obra Tratado da Argumentação, de Perelman e Olbrechts-Tyteca, cuja obra original em francês, intitulada La nouvelle rhétorique: Traité de l'argumentation, foi publicada em 1958. Com ela, os autores instauram no século XX as bases modernas para o estudo da argumentação.

Aristóteles (2005, p. 96-97) $)^{2}$, autor cujas ideias inauguram a noção de ethos, ensinava que as provas produzidas pelo orador e capazes de obter persuasão são de três ordens, cada qual vinculada a um aspecto do discurso. As primeiras, ethos, são dependentes do caráter moral do orador, ou seja, da capacidade de produzir pelo discurso a impressão de ser digno de fé. As segundas, pathos, estão relacionadas à disposição do ouvinte, às emoções que são capazes de sentir e que irão compor base para seu julgamento. Por fim, as últimas, logos, são as que se dão no próprio discurso, pelo que o orador é capaz de nele demonstrar ou fazer parecer por meio do raciocínio.

No campo da retórica da argumentação, Perelman e Olbrechts-Tyteca (1996) lembram que o discurso, como um ato do orador, merece especial atenção pela representação que pode fazer da pessoa e pela sua importância no processo da argumentação. O orador, então, pode ser julgado pelas qualidades que apresenta em seu discurso:

Levando em conta as relações que existem entre a opinião que se tem do orador e a maneira pela qual se julga seu discurso, os antigos mestres de retórica tiraram daí conselhos práticos, recomendando aos oradores darem uma impressão favorável de suas pessoas, atraírem a estima, a benevolência, a simpatia de seu auditório [...] (PERELMAN; OLBRECHTSTYTECA, 1996, p. 362)

\footnotetext{
${ }^{1}$ Disponível em https://www.youtube.com/watch?v=teOkUy74C6o . Acesso em 4 nov. 2019.

${ }^{2}$ Utilizamos a edição de 2005, do Centro de Filosofia da Universidade de Lisboa.
} 
Pelo fato de o discurso não significar sozinho, mas depender ainda de quem o profere, a presunção de confiança pode ser fator determinante para a adesão da opinião do destinatário. Nesse sentido, os autores (op. cit.) afirmam que a pessoa do orador constitui um contexto de influência inegável:

\footnotetext{
Se a pessoa do orador fornece um contexto ao discurso, este último, por outro lado, determina a opinião que dela se terá. $\mathrm{O}$ que os antigos chamavam de etos oratório se resume à impressão que o orador, por suas palavras, dá de si mesmo. (PERELMAN; OLBRECHTS-TYTECA, 1996, p. 363)
}

Discorrendo sobre o ethos aristotélico, Maingueneau (2011) ressalta o efeito da boa impressão pela forma como se elabora o discurso, tornando-o capaz de convencer seu auditório. O discurso (como encenado também por um conjunto de elementos contextuais) deve, por assim dizer, consubstanciar certos aspectos culturalmente associados a determinado comportamento. Sua eficácia, então, deve-se ao fato de, sem estar necessariamente explicitado no enunciado, ele envolver de alguma forma a enunciação. O ethos compreende, assim, a escolha das palavras, dos argumentos, do ritmo e da entonação de seu discurso (MAINGUENEAU, 2005). No entanto, o fato de a fonte do ethos ser o discurso não significa que nele se encerre, pois, sendo efeito, resulta do juízo que o destinatário, alo do discurso, faz da instância enunciadora.

Muito desse efeito pretendido não pressupõe, no entanto, de demonstração pelo raciocínio. Aristóteles (2005, p. 160), no Livro II - $1378 a$, apresenta três causas que tornam o orador persuasivo: "a prudência, a virtude e a benevolência". Aparentar possuir tais qualidades significa para o orador mais chances de obter a confiança do seu público.

As qualidades elencadas por Aristóteles (2005) podem emergir no discurso como ato complexo constituído por diferentes elementos, inclusive podendo ser decorrentes de outros atos sociais realizados previamente pelo orador. Charaudeau (2011), diante disso, ao abordar a problemática de o ethos ser resultado de uma construção discursiva (ethos construído) ou decorrer de uma instância prévia ao discurso (ethos pré-construído), argumenta em favor de uma visão intermediária. Segundo Charaudeau (2011), para construir uma imagem do sujeito que fala, o interlocutor se apoia em dados apreendidos no fio do discurso, mas também se utiliza de informações sobre a pessoa, não só sobre sua configuração como enunciador.

É preciso, dessa forma, considerar o quadro sociolinguageiro (CHARAUDEAU, 2003, 2005b), que determina dois espaços integrados do ato de linguagem. No primeiro, espaço externo, situam-se os contornos que moldam determinada atividade comunicativa: as identidades sociais dos sujeitos em interlocução (Eu comunicante: sujeito social situado no processo de produção; Tu interpretante: sujeito social situado no processo de interpretação), seus propósitos e as coerções envolvidas. No segundo, o interno, as estratégias mobilizadas no delineamento das identidades discursivas (Eu enunciador: sujeito do discurso, ser hipotético situado no processo de produção; Tu destinatário: sujeito do discurso, ser hipotético situado no processo de interpretação) desses interlocutores, adotadas em função das informações do espaço externo. Assim: 
Fazer situacional

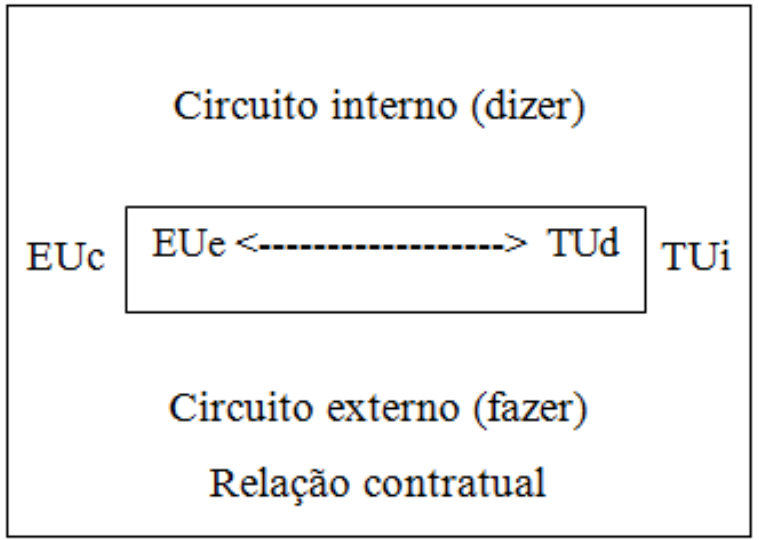

\section{Diagrama 1 - Relação contratual}

Fonte: CHARAUDEAU, 2003, p. 29).

EU enunciador e TU destinatário correspondem a hipóteses construídas, na ocasião do discurso, pelo sujeito social EU comunicante. No entanto, TU interpretante também formula sua imagem de si e de seu interlocutor. Como o quadro comunicativo não pode pressupor via de mão única, postula-se a possibilidade de assimetria entre as imagens construídas pelo comunicante $(\mathrm{EUc}) \mathrm{e}$, no outro lado do processo, também pelo interpretante (TUi). São, portanto, postas em jogo as identidades sociais dos participantes e suas identidades discursivas, estas últimas atribuídas reciprocamente.

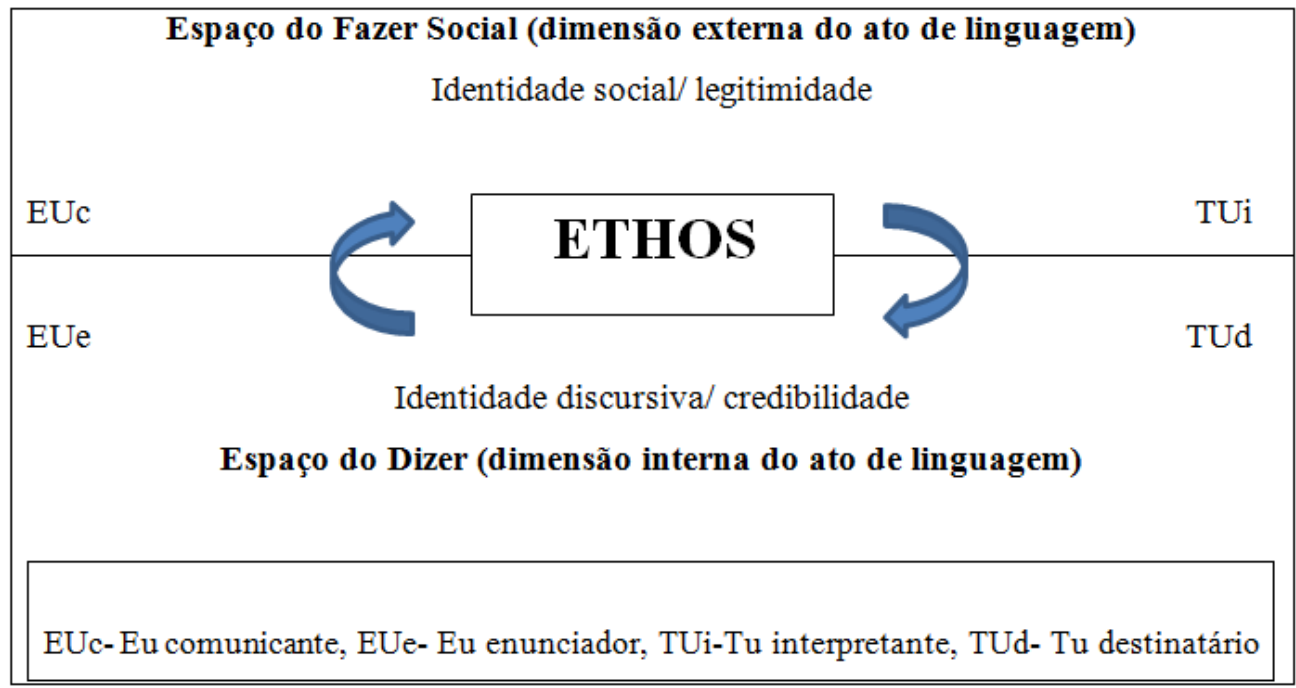

\section{Diagrama 2 - A construção sociodiscursiva do ethos}

Fonte: Elaborado pelo autor.

Charaudeau (2006, p. 344) particulariza a identidade social pela necessidade de ser reconhecida pelos outros. Trata-se, em Semiolinguística, daquilo que confere ao sujeito o direito à palavra, o que sustenta a sua legitimidade, que depende da atuação do sujeito 
nos domínios do saber (fundado nas opiniões, nos saberes compartilhados e no seu manuseio, com vistas à sedução e persuasão do interlocutor) e do poder (estabelecido principalmente a partir dos vínculos institucionais que conferem poder ao sujeito). Já a identidade discursiva, sem se opor à anterior, apenas projetando-se num contínuo, depende não somente de o sujeito saber organizar sua fala, mas principalmente de sua capacidade em parecer digno de crédito, da necessidade de seu interlocutor considerá-lo verdadeiro. Por essa razão, a credibilidade, que depende da identidade discursiva, envolve a formulação de uma imagem de si, um ethos, sendo, pois, necessariamente estratégica. Assim, as relações entre ethos e o quadro sociolinguageiro são sinteticamente apresentadas no diagrama 2, que representa-se (Diagrama 2) a interdependência entre os dois espaços reguladores do ato de comunicação: um contendo determinações sociais (externo), outro discursivas (interno), sendo o ethos realizado, portanto, sociodiscursivamente.

Quanto ao domínio político, Charaudeau (2016, p. 73) explica que legitimidade e credibilidade estão intimamente entrelaçadas. A legitimidade conferida a um candidato pelo voto não é absoluta nem definitiva. É, pois, necessária a manutenção constante dela. Isto passa pelo exercício da credibilidade, que se faz pela linguagem.

Posto isto, privilegiou-se, neste estudo, uma abordagem semiolinguística da noção de ethos (CHARAUDEAU, 2011), aliada a um quadro complementar de estudos do discurso em interação.

\section{A CONSTRUÇÃO DO ETHOS EM INTERAÇÃO NO DEBATE POLÍTICO-ELEITORAL}

Na análise do discurso em interação, Kerbrat-Orecchioni (2008), aplicando a noção de ethos, dedica-se a compreender como o locutor pode ao mesmo tempo construir uma imagem de si e do seu interlocutor. Da noção de ethos, ela distingue a de identidade, que abarca todas as características estáveis ou meramente transitórias que caracterizam um determinado sujeito (estado civil, características físicas e/ou psicológicas, gostos, crenças etc). Segundo ela, "no decurso da interação os locutores vão esforçar-se para 'destacar' alguns traços de sua identidade" (2008, p. 237, grifo da autora), enquanto outros permanecerão convenientemente em stand by.

Quanto ao ethos, reforça Kerbrat-Orecchioni (2008) tratar-se de uma noção mais restrita que a de identidade, uma vez que os indícios são forjados discursivamente. Já os traços que compõem a identidade se ligam ao sujeito independentemente do comportamento discursivo. $\mathrm{Na}$ análise que fez do debate entre Nicolas Sarkozy e JeanMarie Le Pen, ela observa que o status de Ministro do Interior, cargo ocupado por Sarkozy, à época, constituiria um componente de sua identidade. A sua aparente "firmeza", por sua vez, ofereceria impressões de seu ethos.

As delimitações conferidas por Kerbrat-Orecchioni (2008) aos conceitos de ethos e de identidade reforçam o quadro postulado por Charaudeau (2011). Assim, no campo semiolinguístico, o ethos construído resulta da elaboração pelo sujeito enunciador de um projeto de fala, estando, dessa forma, situado no campo do dizer. O ethos constitui-se, portanto, em um dos efeitos hipoteticamente formulados pelo comunicante. Já o ethos 
pré-construído é pertinente ao espaço do fazer social e centra-se no sujeito comunicante. Tal conceito designa noção equivalente à de identidade (KERBRAT-ORECCHIONI, 2008), desenvolvida nos estudos do ethos em interação.

Em estudo sobre o desacordo em debates políticos, Kerbrat-Orecchioni (2016) atesta que esse é um gênero tipicamente orientado para a situação de desacordo, sobretudo em contextos eleitorais de segundo turno. Nessa situação, na qual interessa triunfar sobre o adversário, são os pontos de desacordo que interessam.

Dessa forma, para o estudo do ethos em contexto interacional, é importante distinguir duas noções propostas por Chanay e Kerbrat-Orecchioni (2007): a imagem exibida e a imagem atribuída. A primeira diz respeito à imagem favorável construída de si mesmo, seja por meio de seu ato verbal stricto sensu, seja pelas indicações paraverbais, que tornam possível causar a impressão credível do locutor. Já a segunda trata da imagem construída para o oponente, razão pela qual não pode ser positiva, mas depreciativa, visando refutar sua posição supostamente digna de fé.

É preciso considerar, ainda, o fato de o ethos não ser algo necessariamente estável na interação. No curso de debates eleitorais televisivos, por exemplo, as variações de ethos podem emergir como decorrência de uma necessidade de defesa, pois, como salienta Maingueneau (2020, p. 27), o político está sempre sob "constante ameaça de intervenções desestabilizantes do adversário".

Nessas interações conflituais, a distinção entre ethos dito (as qualificações enunciadas pelo orador sobre si) e ethos mostrado (as qualificações que o orador deixa transparecer por meio do discurso, sem enunciá-las) é central. Como explica Maingueneau (2020, p. 27), cada um dos políticos deverá converter o ethos negativo a si atribuído em ethos positivo. A partir disso, nem sempre haverá uniformidade, pois o ethos mostrado poderá, com efeito, contradizer o ethos dito. Será o caso de um político que afirme textualmente a importância do respeito mútuo entre as pessoas, mas em dado momento do debate eleve o tom de sua voz e vocifere palavras ofensivas contra seu oponente.

\section{DEBATE POLÍTICO-ELEITORAL: O CONFLITO MIDIATIZADO}

O debate político midiático organiza-se, conforme Charaudeau (2005a), em um dispositivo composto por três instâncias de interlocução: o apresentador (que deve gerenciar os turnos de fala e regular as transgressões do debate), os debatedores (geralmente, políticos com notoriedade, selecionados pelo potencial de opiniões conflitantes) e o público (cumprindo o papel de audiência, seja como convidados para o cenário ou espectadores em geral).

No debate político-eleitoral televisionado, mais específico por ocorrer em função de processo eleitoral, a organização se dá também por um dispositivo composto pelas mesmas três instâncias de interlocução: apresentador (A), debatedores (D) e público (P). No entanto, a instância formada pelos debatedores detalha-se por, neste subtipo de debate, admitir configurações diversas. No Brasil, em debates de primeiro turno, é comum a presença de quase todos os candidatos ao cargo público; já em debates de segundo turno, os participantes são apenas os dois candidatos mais votados no primeiro turno. 
Destaca-se a importância do papel central do apresentador do debate, que é o mediador responsável por assegurar o respeito às regras que tornam possível (e menos violento) o evento sociodiscursivo. Abaixo (Diag. 3) representa-se a configuração adotada no debate do dia 25/10/2018, nos estúdios da Rede Globo de Televisão: (A) Ana Paula Araújo e (D) Wilson Witzel e Eduardo Paes. As setas bidirecionais indicam a interlocução direta entre os dois debatedores e as unidirecionais representam a centralidade do apresentador e a possibilidade de os debatedores a ele se reportarem:

(A)

(D)

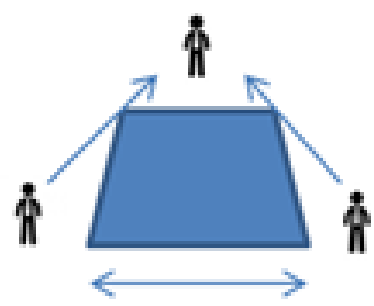

\section{$\pi$}

(P)
(D)

\section{Diagrama 3 - 0 dispositivo de encenação do debate-político eleitoral}

Fonte: Elaborado pelo autor.

Ao público convidado que compõe o cenário é vedada a participação ou quaisquer manifestações que interfiram no curso do debate, o que no diagrama representa-se pelo tracejado. Esta instância é constituída ainda pelo conjunto dos espectadores que acompanham a transmissão.

Nesses debates, é fundamental que os candidatos construam uma imagem credível de si, ou seja, apresentem-se diante do grande público como a alternativa ideal (mais acertada) de governo por possuírem predicados técnicos e morais favoráveis ao cargo. Tal necessidade cerca o político em todas as situações públicas de sua campanha eleitoral, no entanto, o fato de o debate político-eleitoral ser transmitido regional ou nacionalmente e ter o potencial de atingir milhares/milhões de eleitores representa um momento estratégico.

Trata-se de um gênero focalizado no espectador de TV. Por conta disso, além de geralmente ser organizado estruturalmente em blocos e temas para favorecimento da coerência, é eivado de estratégias individuais de convencimento/persuasão do eleitorado. Uma delas, a que neste artigo destacamos, é a formulação do ethos, que se insere em uma atividade discursiva de argumentação. 
Por apresentar uma circunstância material de troca interlocutiva, isto é, não haver um locutor que domine a fala exclusivamente por todo o debate, mas sim ocorrer alternância de turnos, o político tem de enfrentar a fala opositora de seu/s adversário/s. Por essa razão, Kerbrat-Orecchioni (2016) assevera ser o debate político orientado para o desacordo.

Ainda, por ser um evento organizado por uma instância midiática, destaca-se o papel do conflito, que influencia o aumento dos índices de audiência. Nesse sentido, Charaudeau (2010), caracteriza o gênero debate como uma "espetacularização do conflito verbal" (p. 218).

Quanto aos temas próprios ao debate político-eleitoral, ele prioritariamente deve versar sobre tópicos das propostas de governo de cada candidato. Assim, espera-se que o locutor, na ocasião da posse de turno de fala, discorra sobre o que considera ser positivo em sua campanha.

No entanto, nem sempre essa é a tônica do discurso, uma vez que, nesse gênero, a credibilização de si muitas vezes depende da descredibilização do outro. Assim, a elaboração de uma imagem de candidato ideal não se constrói livremente, sem a interferência do adversário. Por isso, como se verá adiante, o político não só gerencia a imagem exibida (favorável de si), como também a imagem atribuída (depreciativa do outro), nos termos de Chanay e Kerbrat-Orecchioni (2007).

\section{O DEBATE DE $2^{\circ}$ TURNO ENTRE EDUARDO PAES (EP) E WILSON WITZEL (WW) 5.1 O CONFRONTO INICIAL}

O início do debate é marcado pelo tom que cada candidato vai imprimir desse ponto em diante. EP começa o primeiro bloco sem cumprimentar o público e seu adversário, descartando, caso o fizesse, a promoção do ethos positivo que demonstra cordialidade. Diferente disso e aparentemente irritado, EP interpela WW sobre seu suposto envolvimento com o advogado Azenha ${ }^{3}$, defensor de Nem, que à época era traficante da favela Rocinha, na cidade do Rio de Janeiro:

(1) EP: Muito objetivamente, ficou comprovado, depois de muitas negativas suas a sua relação com o Azenha. O Azenha é o advogado que botou o Nem, maior traficante do Rio de Janeiro na mala e deu fuga para ele na Rocinha, foi condenado por corromper policial. Numa troca de whatsApp entre você e o Nem, você pede a ele para passar na tua casa para pegar um dinheiro vivo. Afinal de contas, por que esse dinheiro vivo? O que era isso?

WW, por seu turno, não responde a EP com o mesmo tom que este imprimira. Sua opção foi por, calmamente, agradecer à Emissora Rede Globo de Televisão e se dirigir ao público-eleitor, dizendo-lhe que estaria ali no debate para tratar dos problemas do Rio de Janeiro:

\footnotetext{
${ }^{3}$ Luiz Carlos Cavalcanti Azenha 
(2) WW: Eu quero agradecer à Rede Globo de televisão a oportunidade de estarmos aqui e dizer a você eleitor e eleitora, eu estou aqui para discutir os problemas do Rio de Janeiro, os graves problemas que atingem a nossa sociedade. Todas essas questões já estão sendo levadas aos tribunais e essa é uma delas que a justiça, inclusive, determinou que fosse retirada da propaganda do meu adversário, um representante do Cabral e do Pezão.

Outro detalhe que se soma à construção dessas imagens iniciais e que integra/compõe a cena do debate é a forma como cada participante manipula a categoria linguístico-discursiva de pessoa na interlocução. EP se dirige frontalmente a WW, olhando-o quase fixamente, além de utilizar a $2^{\mathrm{a}}$ pessoa do discurso (você) para se referir ao oponente, conforme foi mostrado no trecho (1). Já WW responde à pergunta acusatória de EP, direcionando seu olhar à câmera que o coloca em contato visual com o espectador, propondo-lhe, a partir desse recurso, uma relação de cumplicidade. Além disso, não se dirige diretamente a EP, mas apenas se refere a ele em $3^{\mathrm{a}}$ pessoa, tratando-o por "o meu adversário" e "um representante do Cabral e do Pezão", como se observou no trecho (2). As figuras (1) e (2), a seguir, capturam o posicionamento corporal de cada candidato:

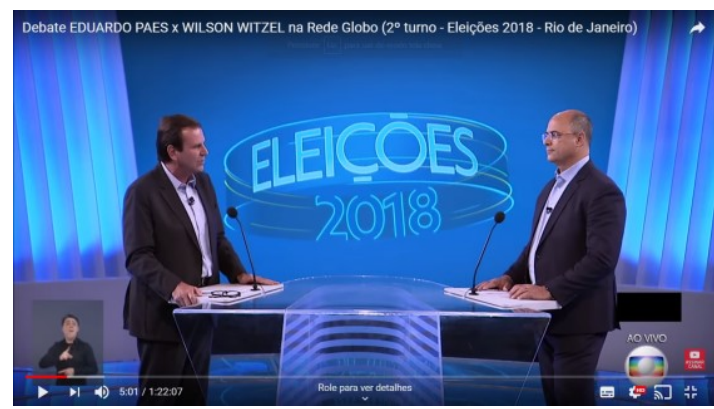

Figura 1 - EP em $1^{\text {a }}$ pessoa

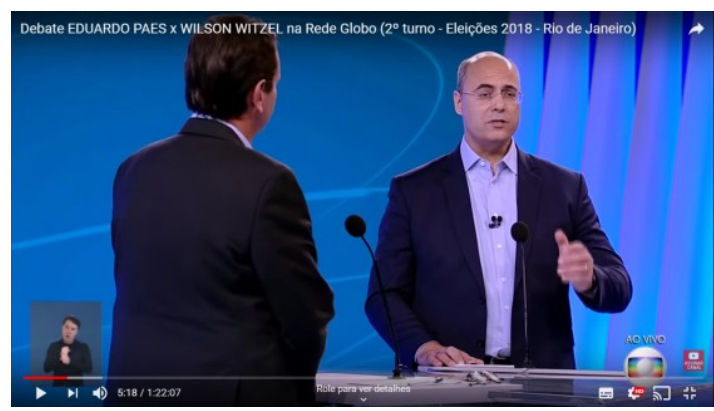

Figura $2-W W$ em $3^{\text {a }}$ pessoa

Fonte: https://www.youtube.com/watch?v=teOkUy74C6o. Acesso em 4 nov. 2019.

WW compõe, assim, um ethos de equilíbrio, ou seja, mantém superficialmente inalteradas suas emoções diante das acusações a ele feitas, de onde se pode deduzir que WW não estivesse preocupado com as afirmações de AP, negando-as com veemência e firmeza:

(3) EP: Eu quero ouvir a sua resposta. Por que dinheiro vivo para o advogado do Nem?

(4) WW: Não dei nenhum dinheiro para absolutamente nenhum advogado do Nem. Eu não tenho nenhuma relação com esse tipo de pessoa.

A calma nas respostas e o aparente desprezo à face do oponente são superposições à sua fala que revelam por meio do discurso o como WW encena a negação à acusação. Uma reação descontrolada, ao contrário, poderia permitir a hipótese de que estaria abalado pela força da verdade. 
Os candidatos no percurso do debate intensificaram o conflito por meio de remissões mútuas às suas identidades (KERBRAT-ORECCHIONI, 2005). Apontar falhas na ética, na honestidade e na eficiência do oponente, recorrendo a aspectos da vida pessoal, profissional e política, teve por objetivo fragilizar a legitimidade (CHARAUDEAU, 2006) dos candidatos, impondo-lhe sérias dificuldades na construção de uma imagem favorável de si.

No curso do debate, o candidato EP foi quem mais atacou diretamente a credibilidade do seu adversário, utilizando-se de dados de sua vida pessoal e profissional. Os temas dos blocos (por exemplo, segurança e habitação) eram abordados nas perguntas tendo acusações como ponto de partida, ou nas respostas, em que eram introduzidos dados desfavoráveis a WW. Este raramente inaugurava o conflito, tentando conduzir o debate no campo das propostas de governo. Quando realizava algum ataque a EP, era quase sempre de forma indireta e geral, fazendo referências ao partido ou à gestão política anterior de EP.

EP atacou incessantemente a identidade de WW acusando-o de manter relações financeiras escusas com o advogado Azenha. Ele fez sucessivas interpelações, inclusive utilizando-se do seu próprio tempo destinado a responder uma pergunta. EP, exigindo textualmente de WW uma resposta, questionou o fato de seu oponente não responder às perguntas e afirmou que o objetivo do debate era esclarecer o público. Com isso, constrói para si o efeito de uma imagem oposta ao caráter que intenta expor de WW: atribui a si o ethos da verdade, por apontar no outro a ausência dessa qualidade.

EP questiona, ainda, o desempenho de WW no cargo pregresso de juiz. Note-se que WW faz recorrentes referências ao fato de ter exercido o cargo de juiz, direcionando esse atributo de sua identidade para que se tornasse o principal alicerce da sua campanha contra a corrupção.

$\mathrm{EP}$, todavia, tenta macular essa legitimidade:

(5) EP: Vejam o portal G1, 11 de agosto de 2011, uma entrevista dele, não é fake. Ele diz que, ameaçado, pediu pra sair e foi pra uma vara de fazenda pública aqui. Então esse seu combate à corrupção, a gente vai tratar disso um pouco mais tarde, não é uma verdade.

Charaudeau (2006) explica que a legitimidade se funda no poder institucional, além dos conhecimentos do sujeito comunicante. No caso de WW, o cargo de juiz lhe conferia um determinado prestígio social, além de estar associado a uma conduta moral e ética modelar, oferecendo-lhe sustentação para falar como alguém reto e probo. É esse ethos que EP tenta deslegitimar:

(6) EP: O candidato Witzel quando era juiz recebia sempre acima do teto, chegou a receber $81.000,00$ reais. Apesar de ter uma casa própria, ele ganhava auxílio moradia, ganhou mais de meio milhão de auxílio moradia em oito anos, uma vergonha, mesmo assim, ficou devendo IPTU. Você acha que isso é um exemplo de conduta ética, moral, de quem não gosta de mordomia, de quem quer governar o Estado do Rio de Janeiro? 
Como destacado em (5) e (6), EP questiona o ethos da honestidade, que WW sempre constrói em sua fala, ao se colocar como a opção de governo para acabar com a corrupção no Estado, como em: "E é por essa razão que eu, um cidadão dignado, resolvi ser candidato a governador" (W.W.).

Em um debate, os candidatos necessitam destacar os pontos positivos do seu plano de governo e, na medida do possível, apontar falhas na proposta adversária. Já no segundo turno, a situação é diferente, pois a propaganda eleitoral já foi veiculada, bem como os debates anteriores em que os candidatos puderam apresentar sua proposta. Em segundo turno, devido ao pouco tempo restante antes do voto, prevalece a urgência de mostrar ao público que o concorrente não deve ser o escolhido. Para tanto, é lugar comum o ataque às identidades (KERBRAT-ORECCHIONI, 2008) ou ethos pré-construído (CHARAUDEAU, 2011), ao mesmo tempo em que há uma tentativa de construção de um ethos, principalmente, de honestidade e de eficiência.

O debate impôs a WW que se posicionasse mais no campo da defesa do que no campo do ataque. A razão primeira e evidente era sua liderança nas intenções de voto. Outro ponto importante era em relação a dados do pré-construído, quanto à experiência política de cada um.

EP vinha de uma recente gestão da Prefeitura da Cidade do Rio de Janeiro em um período de grande injeção de recursos financeiros para obras das Olimpíadas de 2016. Passados dois anos do fim dessa gestão, mantêm-se os bônus e surgem os ônus.

WW, diferentemente, não havia tido ainda experiência política, pois exercia o cargo de juiz. Essas condições explicam, em parte, a natureza dos ataques. Da parte de EP, a tentativa de descredibilização de WW tinha como alvo a vida profissional e pessoal de seu oponente. Da parte de WW, o foco recaiu na gestão da Prefeitura do Rio de Janeiro, cargo de Prefeito ocupado por EP:

(7) WW: Olha, fizeram copa do mundo, olimpíada, Porto Maravilha, gastou- se mais de 40.000.000.000 de reais em obras superfaturadas, e agora nós estamos descobrindo aí, o BRT é uma delas, não foi fiscalizado. Então isso é um grave erro, que a prefeitura cometeu na gestão do candidato adversário, o candidato do Cabral e do pezão.

O trecho anterior flagra parte do debate em que o tema sorteado foi a CEDAE ${ }^{4}$. Os candidatos apresentaram sua visão para a gerência da empresa, momento em que EP faz referência à sua atuação na gestão da Prefeitura: “(...) quando fui prefeito do Rio fiz uma grande concessão de saneamento na Zona Oeste da cidade, e isso melhorou muito o esgoto" (E.P.). Essa é uma imagem exibida (CHANAY; KERBRAT-ORECCHIONI, 2007) inserida na sua fala para apoio da construção de seu ethos de eficiência.

WW, então, conforme (7), refuta o ethos da eficiência construído por EP, atacando dados de sua identidade, conferindo-lhe uma imagem atribuída (CHANAY; KERBRATORECCHIONI, 2007) comprometedora, uma vez que vincula sua gestão à corrupção por superfaturamento nas obras.

\footnotetext{
${ }^{4}$ Companhia Estadual de Águas e Esgotos (CEDAE).
} 
Ainda sobre (7), chamamos a atenção para a forma atenuada de confronto empregada por WW (Fizeram e gastou-se são formas de indeterminação do sujeito ou do autor da ação. Já candidato adversário revela um uso refinado da polidez como forma de agressão.), tom que imprimira até quase a metade do debate, quando, então, passou a adotar forma menos pacífica frente a seu oponente.

Em (8), pode-se já observar mudança no tom de WW ao sinalizar dados negativos da identidade de EP:

(8) WW: Olha, se tivesse tido tanta preocupação assim com as habitações deveria ter diminuído a quantidade de habitações nas comunidades. As comunidades no seu governo como prefeito elas cresceram, elas aumentaram. E, o legado olímpico foi apenas um legado de corrupção $\mathrm{e}$, infelizmente, não deu atenção às comunidades, quer dizer, estas pessoas hoje continuam pisando na lama; continuam sem moradia e nós precisamos utilizar espaços para ter a expansão imobiliária.

A abertura da fala pelo marcador olha, além da construção condicional se tivesse...deveria (com uso do verbo dever) indicam um tom de irritação acima do que WW vinha deixando transparecer por meio do ethos do equilíbrio. Note-se, também, neste momento do debate, o uso da segunda pessoa do discurso (seu governo) como forma mais enfática de se referir ao adversário. A pouca frequência do uso da segunda pessoa pode ser interpretada como uma possível estratégia linguística para evitar o direito de resposta ao adversário, o que é previsto quando este é citado e se julga pessoalmente ofendido.

A seguir (Quadro 1), reúnem-se algumas ocorrências de fala pinçadas do curso durante o debate. Na coluna identidade, há trechos em que os candidatos mobilizam dados de sua identidade para produzir um ethos positivo sobre si. Na coluna ethos, a interpretação desse efeito:

\begin{tabular}{|c|c|c|}
\hline & Identidade & Ethos \\
\hline \multirow[t]{2}{*}{ EP } & $\begin{array}{l}\text { Olha, primeiro, eu fui prefeito do Rio } 8 \text { anos, se desmontou o esquema de } \\
\text { caixinha da FETRANSPOR do Rio de Janeiro. Mais uma vez você não viu } \\
\text { qualquer envolvimento meu ou de qualquer pessoa da prefeitura, nesse caso. }\end{array}$ & Ethos da honestidade \\
\hline & $\begin{array}{l}\text { O que a gente fez nesse caso, na cidade do Rio? A gente fez a licitação das } \\
\text { empresas de ônibus, criamos } 4 \text { consórcios; implantamos o bilhete único, né, } \\
\text { baixou muito o preço na possibilidade das pessoas fazerem } 2 \text { viagens num tempo } \\
\text { adequado. }\end{array}$ & Ethos da eficiência \\
\hline \multirow[t]{2}{*}{ WW } & $\begin{array}{l}\text { Eu fui juiz federal durante } 17 \text { anos, tô acostumado a dar decisões dificílimas } \\
\text { envolvendo a vida das pessoas. }\end{array}$ & Ethos da eficiência \\
\hline & $\begin{array}{l}\text { Deixei a magistratura, hoje estou dedicado a esta campanha politica e } \\
\text { trabalhando nos meus escritórios, na medida como posso. E é assim que vamos } \\
\text { levar a dignidade para o estado do Rio de Janeiro, eu tenho um passado limpo. }\end{array}$ & Ethos da honestidade \\
\hline
\end{tabular}

\section{Quadro 1 - Identidade e ethos}

Fonte: Elaborado pelo autor.

A tese de Kerbrat-Orecchioni (2016) acerca de o debate político-eleitoral ser orientado para o desacordo, sobretudo em contextos de segundo turno, reforça-se aqui, pois atesta-se que a emergência desse processo se faz pela desconstrução dessas imagens de si arroladas pelos candidatos adversários. 
Para exemplificar um pouco mais como o debate de fato é orientado para o desacordo, abaixo (Quad. 2), são mostradas mais ocorrências de uso da imagem exibida feita para si pelo candidato e da imagem atribuída ao adversário:

\begin{tabular}{|c|c|c|}
\hline & $\begin{array}{l}\text { Imagem exibida } \\
\text { (positiva para si) }\end{array}$ & $\begin{array}{l}\text { Imagem atribuída } \\
\text { (negativa para o outro) }\end{array}$ \\
\hline \multirow[t]{2}{*}{ EP } & $\begin{array}{l}\text { Olha, você vê que mesmo nessas circunstâncias, } \\
\text { nessas condições não há qualquer escândalo } \\
\text { envolvendo o sistema de transportes da } \\
\text { Prefeitura do Rio de Janeiro. }\end{array}$ & $\begin{array}{l}\text { Aliás, é curioso que ele diz que é mais caro que São } \\
\text { Paulo, só se for agora com o seu prefeito e padrinho } \\
\text { que apoia sua candidatura, o Crivella. }\end{array}$ \\
\hline & $\begin{array}{l}\text { Você que anda pelo túnel Marcelo Alencar, você } \\
\text { que anda de VLT, você que anda pela } \\
\text { TransOlímpica pra chegar em Nova Iguaçu, pra } \\
\text { chegar na Zona Oeste, pra ir pra Barra da } \\
\text { Tijuca, pra ir pra Jacarepaguá, você que tem } \\
\text { hoje metade já da população da Zona Oeste com } \\
\text { saneamento básico chegando na porta, essas } \\
\text { todas foram PPPs e concessões desenvolvidas } \\
\text { no meu governo, e são elementos } \\
\text { importantíssimos. }\end{array}$ & $\begin{array}{l}\text { Olha, uma das cenas mais dantescas que eu já vi na } \\
\text { minha trajetória política, nessa eleição esse ano, } \\
\text { você que se diz uma pessoa que defende os valores } \\
\text { cristãos, foi a celebração, o enaltecimento da morte } \\
\text { da vereadora Marielle, num evento em que se } \\
\text { rasgou lá a placa, um ser humano, uma pessoa. }\end{array}$ \\
\hline \multirow[t]{2}{*}{ WW } & $\begin{array}{l}\text { Eu fiz mestrado, eu fiz doutorado, eu trabalhei } \\
\text { pra poder ensinar. Então eu tenho convicção de } \\
\text { que tudo na minha vida que eu fiz, foi com } \\
\text { esforço, foi com dedicação, foi superando } \\
\text { desafios. Eu nunca fui uma pessoa que tive vida } \\
\text { boa não candidato do Cabral e do Pezão. }\end{array}$ & $\begin{array}{l}\text { Um indecente voce imaginar que o governador do } \\
\text { estado do Rio de Janeiro pendurado numa liminar } \\
\text { no Tribunal Superior Eleitoral, que foi condenado } \\
\text { pela justiça eleitoral porque desviou } 7.000 .000 \text { de } \\
\text { reais para o plano de governo, isso sim que eu acho } \\
\text { esquisito. }\end{array}$ \\
\hline & $\begin{array}{l}\text { Eu fui juiz da execução fiscal e sei da } \\
\text { dificuldade que é fazer o controle do combate à } \\
\text { sonegação e conversei com alguns técnicos da } \\
\text { auditória da fazenda para que nós possamos ter } \\
\text { mais efetividade no combate a sonegação. }\end{array}$ & $\begin{array}{l}\text { Olha, essa é a versão dos fatos que você tá } \\
\text { apresentando que não corresponde a realidade. } \\
\text { Mais uma vez você mente, distorce a realidade, } \\
\text { distorce os fatos e eu jamais comemorei esse tipo de } \\
\text { coisa. }\end{array}$ \\
\hline
\end{tabular}

\section{Quadro 2 - Imagem exibida e imagem atribuída}

Fonte: Elaborado pelo autor.

São ataques de diversas ordens: ético-morais, profissionais e até religiosos, que objetivam vincular o adversário a valores negativos dentro dessas mesmas categorias.

\section{CONSIDERAÇÕES FINAIS}

No estudo, procuramos compreender como os candidatos Wilson Witzel e Eduardo Paes utilizaram-se da construção de ethé favoráveis à defesa de suas candidaturas. Além disso, diante da tensão desse embate discursivo, decorrente da interação face a face entre os adversários no segundo turno das eleições, propusemo-nos a investigar como foram mobilizados dados prévios ao discurso no gerenciamento da construção dos seus ethé e na descredibilização do ethos alheio.

A análise dos dados demonstrou que o papel das identidades foi fundamental no curso do debate na tentativa de defesa da imagem credível de si que o político intentava construir. Assim, os participantes se viram, constantemente, diante da necessidade de adotar um discurso autocongratulatório na exposição de suas qualidades ético-morais, intelectuais e profissionais. Esses dados extraídos de suas identidades concorreram para a construção de diferentes ethé, dos quais destacamos o de eficiência e o de honestidade. 
No entanto, na mesma medida, também os dados das identidades do adversário foram utilizados para destruir sua imagem frente ao público. Assim, os candidatos, tanto na formulação de perguntas, quanto na de respostas (muitas vezes desviando-se do tópico) acusaram-se mutuamente de corrupção, de manterem relações com aliados de caráter publicamente questionável, de serem ineficientes ou não possuírem expertise necessária em algum assunto.

Para além dessas considerações gerais, o que se observou mais pontualmente foi que os candidatos se apresentaram para o segundo turno com objetivos semelhantes, mas com tarefas diferentes. Eduardo Paes precisava recuperar no segundo turno a baixa expressividade obtida nas urnas no primeiro turno. Para tanto, não bastava retomar seu plano de governo e expor suas principais ideias. A tarefa era descredibilizar a imagem de Wilson Witzel muito mais do que apontar falhas no seu plano de governo, e por essa razão, a seleção de dados da identidade deste circunscreveram detalhes da sua vida íntima, familiar, por exemplo, e profissional, pondo em dúvida o ethos da honestidade que lhe era tão caro.

Já Wilson Witzel, apesar dos confortáveis 41,28\% de votos obtidos no primeiro turno, precisava evitar que Eduardo Paes conquistasse a grande parcela dos votos válidos destinados aos demais concorrentes nessa fase. Era importante arrolar argumentos que o defendessem dos ataques de Eduardo Paes a seus ethé. Parece ter sido profícua a estratégia de ocupar pelo menos $1 / 4$ do debate evadindo-se do confronto com o adversário, construindo de si uma imagem pacífica e equilibrada, inclusive demonstrando cordialidade ao público, desculpando-se pelo comportamento do adversário e afirmando textualmente sua intenção de ali debater programas de governo.

Por fim, tendo em vista que o objetivo do estudo foi analisar o papel da construção do ethos em interação, e não o resultado das eleições, consideramos que os dois candidatos adotaram estratégias discursivas coerentes às posições em que relativamente se encontravam na disputa. Cabia a Eduardo Paes a todo custo tentar mostrar ao público que Wilson Witzel não correspondia à imagem que construía. Cabia a Wilson Witzel tentar sustentá-la.

\section{REFERÊNCIAS}

AMOSSY, R. Ethos (verbete). In: CHARAUDEAU, P; MAINGUENEAU, D. Dicionário de análise do discurso. Trad. Fabiana Komesu. São Paulo: Contexto, 2004.

ARISTÓTELES. Retórica. Trad. Manuel Alexandre Junior, Paulo Farmhouse Alberto e Abel do Nascimento Pena. Centro de Filosofia da Universidade de Lisboa. Lisboa: Imprensa Nacional-Casa da Moeda, 2005.

CHANAY, H. DE; KERBRAT-ORECCHIONI, C. 100 minutes pour convaincre : l'éthos en action de Nicolas Sarkozy. In: M. BROTH et al. (Org.). Le français parlé des médias: actes du colloque de Stockholm, 8-12 juin 2005, Stockholm, Université de Stockholm (Acta Universitatis Stockholmiensis/ 24), 2007.

CHARAUDEAU, P. Uma teoria dos sujeitos da linguagem. In: MARI, H; MACHADO, I; MELLO, R. Análise do discurso: fundamentos e práticas. Belo Horizonte: Nad-FALE-UFMG, 2003.

CHARAUDEAU, P. Les médias et l'information: L'impossible transparence du discours. De Boeck - Ina coll. Médias Recherches, Bruxelles, 2005a. 
CHARAUDEAU, P. Uma análise semiolinguística do texto e do discurso. In: PAULIUKONIS, M. A. L; GAVAZZI, S. (Org.) Da língua ao discurso: reflexões para o ensino. Rio de Janeiro : Lucerna, 2005b, p. 11-27.

CHARAUDEAU, P. Identité sociale et identité discursive, le fondement de la compétence communicationnelle. Gragoatá, Niterói, v. 11, n. 21, p. 339-354, 2ºm. 2006.

CHARAUDEAU, P. Discurso das Mídias. 2. ed. São Paulo: Contexto, 2010.

CHARAUDEAU, P. Discurso Político. 2. ed. São Paulo: Contexto, 2011.

CHARAUDEAU, P. A conquista da opinião pública: como o discurso manipula as escolhas políticas. São Paulo: Contexto, 2016.

KERBRAT-ORECCHIONI, C. A construção mútua das identidades nos debates políticos na televisão. In: LARA, G; MACHADO, I; EMEDIATO, W. (Org.). Análise do discurso hoje. v. 2. Rio de Janeiro: Nova Fronteira, 2008.

KERBRAT-ORECCHIONI, C. Le désaccord, réaction "non préférée"? Le cas des débats présidentiels, Cahiers de Praxématique, n. 67, 2016. Disponível em: http://praxematique.revues.org/4524. Acesso em: 22 fev. 2019.

MAINGUENEAU, D. Ethos, cenografia, incorporação. In: AMOSSY, R. Imagens de si no discurso: a construção do ethos. São Paulo: Contexto, 2005.

MAINGUENEAU, D. A propósito do ethos. In: MOTTA, A; SALGADO, L (Org.). Ethos discursivo. 2. ed. São Paulo: Contexto, 2011a. p. 11-30.

MAINGUENEAU, D. Análise de textos de comunicação. Trad. Cecília Souza-e-Silva e Décio Rocha. 6. ed. São Paulo: Cortez, 2011b.

MAINGUENEAU, D. Variações sobre o ethos. Trad. Marcos Marcionilo. São Paulo: Parábola, 2020.

PERELMAN, C; OLBRECHTS-TYTECA, L. Tratado da argumentação - nova retórica. Trad. Maria Galvão. São Paulo: Martins Fontes, 1996.

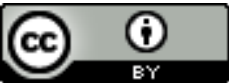

Este texto está licenciado com uma Licença Creative Commons Atribuição 4.0 Internacional. 